\title{
ARTERIAL PATTERN OF THE KIDNEY IN A BANGLADESHI POPULATION - A POSTMORTEM STUDY
}

\author{
JOHORA F ${ }^{1}$, NURUNNABI ASM ${ }^{2}$, SIDDIQUA D ${ }^{3}$, PERVEN HA $^{4}$, ARA $^{5}$ \\ Abstract \\ Context: The kidney is a highly vascular organ in the human body. The aim of the present \\ study was to see the variations in perihilar branching pattern and morphology of the main renal \\ arteries in a Bangladeshi population based on autopsy.
}

\begin{abstract}
Methods: This cross-sectional, descriptive study was done in the Department of Anatomy, Dhaka Medical College, Dhaka, from July 2008 to June 2009, based on collection of 140 post mortem human kidneys from 70 unclaimed dead bodies which were in the morgue. All the samples were divided into three age-groups: A (10-19 years), B (20-39 years) and C (40-59 years). Morphological examination was done to identify main renal arteries and accessory renal arteries with their sites of origin and perihilar branching pattern of the renal arteries as well. The length of the renal artery was measured by using a measuring tape. Besides, renal angiography was done to see the intrarenal branching pattern.

Results: The length of the right and left renal arteries were found $3.09 \pm 0.08 \mathrm{~cm}$ and $2.09 \pm 0.09$ $\mathrm{cm} ; 3.48 \pm 0.17 \mathrm{~cm}$ and $2.34 \pm 0.17 \mathrm{~cm} ; 3.88 \pm 0.17 \mathrm{~cm}$ and $2.81 \pm 0.16 \mathrm{~cm}$ in group $A, B$ and $C$ respectively. The length of the right renal artery was found greater than of the left $(P<0.001)$ in all age-groups. Besides, age related changes were also found in the length of the renal arteries $(P<0.001)$. Accessory renal arteries were present in the right side in 33.4\%, 23.35 and 33.3\% specimens in group $A, B$ and $C$ respectively, while in the left side, in $59.7 \%, 27.9 \%$ and $13.4 \%$ in group $A, B$ and $C$ respectively. The number of anterior divisions of the both renal arteries were 2 in 8.3\%, 3 in 12.5\% and 4 in 79.2\% specimens in group A, while in group B, 2 in 7\%, 3 in $17.4 \%$ and 4 in $75.6 \%$ specimens, and in group C, 2 in $3.3 \%, 3$ in 3.3\% and 4 in $93.3 \%$ specimens. Number of posterior division was found only 1 in all the groups. Renal angiography revealed intrarenal branching pattern which showed segmental arteries divided into several lobar arteries and interlobar arteries.
\end{abstract}

Key words: Kidney, arterial pattern of kidney, branches of renal artery, renal angiography.

J Dhaka Med Coll. 2015; 24(1) : 12-16.

\section{Introduction}

The kidneys are highly vascular organs in the human body ${ }^{1}$ which serve to convert more than 1700 litres of blood per day into about 1 litre of highly specialized concentrated fluid called urine'2. Renal arteries arise from abdominal aorta and supply the kidneys through a number of its subdivisions ${ }^{3,4}$. Near the renal hilum, each renal artery divides into anterior and posterior divisions (presegmental arteries), which further divide into segmental arteries (apical, upper, middle, inferior and posterior) supplying the renal arterial segments ${ }^{3}$. Then smaller lobar and interlobar branches are extended in the peripheral renal mass ${ }^{4,5}$. Variations in the renal arteries are not uncommon in general population with different frequencies among several ethnic and racial groups ${ }^{6}$. These variations are becoming more important considering the gradual increase in the number of interventional radiological procedures, as well as increasing number of renal transplants, vascular reconstructions, various endourologic procedures and

1. Dr. Fatema Johora, Assistant Professor, Department of Anatomy, OSD, Directorate General of Health Services (DGHS), Dhaka.

2. Dr. Abu Sadat Mohammad Nurunnabi, Assistant Professor, Department of Anatomy, OSD, Directorate General of Health Services (DGHS), Dhaka.

3. Dr. Dilruba Siddiqua, Associate Professor, Department of Anatomy, Ibn Sina Medical College, Dhaka.

4. Dr. Hosna Ara Perven, Associate Professor, Department of Anatomy, The Medical College for Women \& Hospital, Uttara, Dhaka.

5. Prof. Shamim Ara, Professor \& Head, Department of Anatomy, Dhaka Medical College, Dhaka.

Correspondence: Dr. Abu Sadat Mohammad Nurunnabi, Assistant Professor, Department of Anatomy, OSD, Directorate General of Health Services (DGHS), Dhaka. Cell Phone: +881712290608, Email: shekhor19@yahoo.com 
interventional techniques ${ }^{7,8}$. Besides, a comprehensive knowledge of the renal vasculature remains a key issue in determining the technical feasibility of surgical intervention as well as post operative patient management ${ }^{8,9}$. Hence, the present study was designed to identify the variations in perihilar branching pattern and morphology of the main renal arteries in a Bangladeshi population and to compare with previous local and foreign studies. The findings of the study are expected to contribute to the knowledge pool on variational anatomy of the renal arterial pattern.

\section{Methods}

This cross-sectional, descriptive study was done in the Department of Anatomy, Dhaka Medical College, Dhaka, from July 2008 to June 2009, based on collection of 140 post mortem human kidneys collected from 70 unclaimed dead bodies which were under examination in the morgue of the Department of Forensic Medicine, Dhaka Medical College, Dhaka. All the samples were taken from medicolegal cases. For convenient description of changes of the morphological dimensions of the kidney in relation to age, the collected samples were divided into three age-groups including A (1019 years), B (20-39 years) and C (40-59 years), according to Darmady et al. $^{2}$, (Table-I).

Table-I

Age distribution of the samples of the present study $(n=140)$

\begin{tabular}{lrcc}
\hline \multicolumn{2}{c}{ Age group } & Age limitin & \multicolumn{2}{c}{ Number of samples } \\
& years & Right Kidney Left kidney \\
\hline A & $10-19$ & 12 & 12 \\
B & $20-39$ & 43 & 43 \\
C & $40-59$ & 15 & 15 \\
\hline
\end{tabular}

Both the kidneys with its supplying arteries were taken on the tray for each cadaver and at first, all possible variations were observed in the origin of renal arteries. Then the measurement of the length of the renal artery was taken from the point of its origin to the point of its division near the hilum, by using a measuring tape (according to Mullick ${ }^{6}$ ).

Presence or absence of accessory renal arteries was observed and if found, the site of origin was noted down. Perihilar branching pattern of the renal arteries was also observed and numbers of anterior and posterior divisions were noted down.

To observe the intrarenal vascular pattern, renal angiography was done by injecting a contrast medium, e.g. iopamidol, into the renal arteries and their branches. 3 relatively fresh samples from group A, 5 from group B and 3 from group $\mathrm{C}$ were taken for this purpose. Those samples were washed thoroughly with normal saline at room temperature $\left(37^{\circ} \mathrm{C}\right)$ until clear fluid came out of the venules. Iopamidol was injected into the renal arteries by using a $50 \mathrm{cc}$ syringe and the arteries were ligated immediately to prevent back flow. Then radiological pictures were taken as soon as possible (according to Boijsen ${ }^{10}$ ).

The data collected were processed and statistical analyses were done by using SPSS version 13.0. The comparison between the right and the left was done by using unpaired Student's ' $t$ ' test and in between different groups by One-way ANOVA test. Besides, comparison between arterial branching patterns was done by Chi-square test. The present study was approved by the Ethical Review Committee of Dhaka Medical College, Dhaka.

\section{Results}

The length of the right and left renal arteries were found $3.09 \pm 0.08 \mathrm{~cm}$ and $2.09 \pm 0.09 \mathrm{~cm}$; $3.48 \pm 0.17 \mathrm{~cm}$ and $2.34 \pm 0.17 \mathrm{~cm} ; 3.88 \pm 0.17 \mathrm{~cm}$ and $2.81 \pm 0.16 \mathrm{~cm}$ in group $\mathrm{A}, \mathrm{B}$ and $\mathrm{C}$ respectively (table-II). The length of the right renal artery was found greater than of the left $(\mathrm{P}<0.001)$ in all age-groups. Besides, age related changes were also found in the length of the renal arteries $(\mathrm{P}<0.001)$ (table-II). Accessory renal arteries were present in the right side in $33.4 \%, 23.35 \%$ and $33.3 \%$ specimens in group $\mathrm{A}, \mathrm{B}$ and $\mathrm{C}$ respectively, while in the left side, in $59.7 \%, 27.9 \%$ and $13.4 \%$ in group A, B and $\mathrm{C}$ respectively (table-III, fig. 1). The number of anterior divisions of the both renal arteries were 2 in $8.3 \%, 3$ in $12.5 \%$ and 4 in $79.2 \%$ specimens in group A, while in group B, 2 in $7 \%, 3$ in $17.4 \%$ and 4 in $75.6 \%$ specimens, and in group C, 2 in 3.3\%, 3 in 3.3\% and 4 in $93.3 \%$ specimens (table-IV). Number of posterior division was found only 1 in all the groups. Intrarenal branching showed segmental arteries divided into several lobar arteries and interlobar arteries (fig. 2). 
Table-II

Length of right and left renal artery in different age group

\begin{tabular}{|c|c|c|c|}
\hline \multirow[t]{2}{*}{$\overline{\text { Age Group }}$} & \multicolumn{2}{|c|}{ Length of renal artery in $\mathrm{cm}$} & \multirow[t]{2}{*}{$\mathrm{P}$ value } \\
\hline & RightMean \pm SD & LeftMean \pm SD & \\
\hline $\mathrm{A}(\mathrm{n}=12)$ & $3.09 \pm 0.08(3.00-3.20)$ & $2.09 \pm 0.09(2.00-2.20)$ & $<0.001^{* * *}$ \\
\hline$B(n=43)$ & $3.48 \pm 0.17(3.10-3.90)$ & $2.34 \pm 0.17(2.00-2.70)$ & $<0.001^{* * *}$ \\
\hline \multirow[t]{2}{*}{$C(n=15)$} & $3.88 \pm 0.17(3.70-4.10)$ & $2.81 \pm 0.16(2.40-3.10)$ & $<0.001^{* * *}$ \\
\hline & $\mathrm{P}$ value & $P$ value & \\
\hline A vs $B$ & $<0.001^{* * *}$ & $<0.001^{* * *}$ & \\
\hline A vs $\mathrm{C}$ & $<0.001^{* * *}$ & $<0.001^{* * *}$ & \\
\hline $\mathrm{B}$ vs $\mathrm{C}$ & $<0.001^{* * *}$ & $<0.001^{* * *}$ & \\
\hline
\end{tabular}

Figures in the parentheses indicate range. Comparison between right and left side done by unpaired Student's ' $t$ ' test and comparison between different age groups done by One-way ANOVA (PostHoc), ${ }^{* * *}=$ significant.

Table-III

Site of origin of right and left accessory renal artery in different age group

\begin{tabular}{|c|c|c|c|c|c|}
\hline $\begin{array}{l}\text { Age } \\
\text { group }\end{array}$ & $\begin{array}{c}\text { Absent } \\
\text { Number (\%) }\end{array}$ & $\begin{array}{l}\text { Abdominal } \\
\text { Aorta } \\
\text { Number (\%) }\end{array}$ & $\begin{array}{c}\text { Upper Polar } \\
\text { Artery } \\
\text { Number (\%) }\end{array}$ & $\begin{array}{c}\text { Superior } \\
\text { Mesenteric Artery } \\
\text { Number }(\%)\end{array}$ & $\begin{array}{c}\mathrm{P} \\
\text { value }\end{array}$ \\
\hline \multicolumn{6}{|c|}{ Right side } \\
\hline $\mathrm{A}(\mathrm{n}=12)$ & $8(66.7)$ & $2(16.7)$ & $2(16.7)$ & - & \multirow{3}{*}{$>0.50^{\mathrm{ns}}$} \\
\hline$B(n=43)$ & $33(76.7)$ & 7 (16.3) & $3(7.0)$ & - & \\
\hline$C(n=15)$ & $10(66.7)$ & $3(20.0)$ & $2(13.3)$ & - & \\
\hline \multicolumn{6}{|l|}{ Left side } \\
\hline $\mathrm{A}(\mathrm{n}=12)$ & $5(41.7)$ & $4(33.3)$ & $2(16.7)$ & $1(8.3)$ & \multirow{3}{*}{$>0.10^{\mathrm{ns}}$} \\
\hline$B(n=43)$ & $31(72.1)$ & 8 (18.6) & $4(9.3)$ & - & \\
\hline$C(n=15)$ & $13(86.7)$ & $1(6.7)$ & $1(6.7)$ & - & \\
\hline
\end{tabular}

Figures in the parentheses indicate percentage. Statistical analysis done by Chi-square test, ns $=$ not significant.

Table-IV

Number of anterior divisions of (right plus left) renal arteries in different age group

\begin{tabular}{lcccc}
\hline Age group & $\begin{array}{c}2 \text { divisions } \\
\text { Number }(\%)\end{array}$ & $\begin{array}{c}3 \text { divisions } \\
\text { Number }(\%)\end{array}$ & $\begin{array}{c}4 \text { divisions } \\
\text { Number }(\%)\end{array}$ & \begin{tabular}{c} 
value \\
\hline A $(\mathrm{n}=24)$
\end{tabular} \\
B $(\mathrm{n}=86)$ & $6(8.3)$ & $3(12.5)$ & $19(79.2)$ & \\
$\mathrm{C}(\mathrm{n}=30)$ & $1(3.3)$ & $15(17.4)$ & $65(75.6)$ & $>0.10^{\mathrm{ns}}$ \\
\hline
\end{tabular}

Figures in the parentheses indicate percentage. Statistical analysis done by Chi-square test, $\mathrm{ns}=$ not significant. 


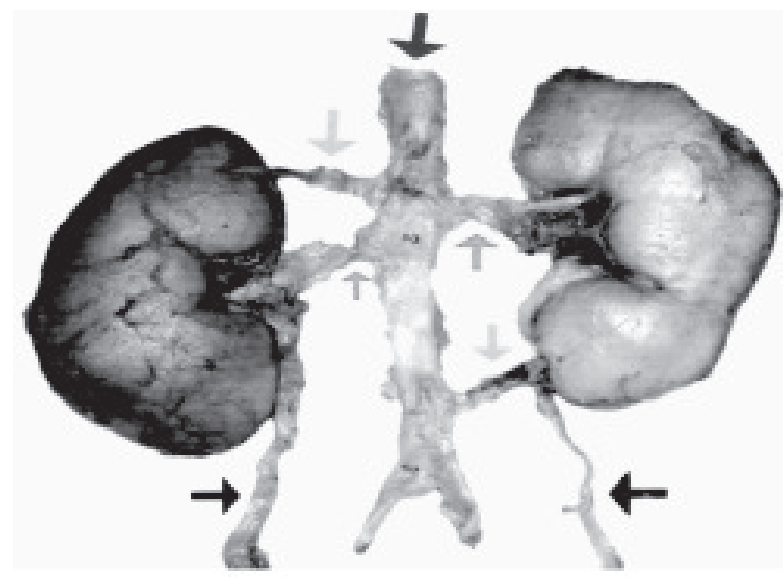

Fig. 1. Photograph showing accessory renal arteries (yellow arrows), main renal arteries (green arrows), abdominal aorta (red arrow) and ureters (black arrows), taken from group A (10-19 years).

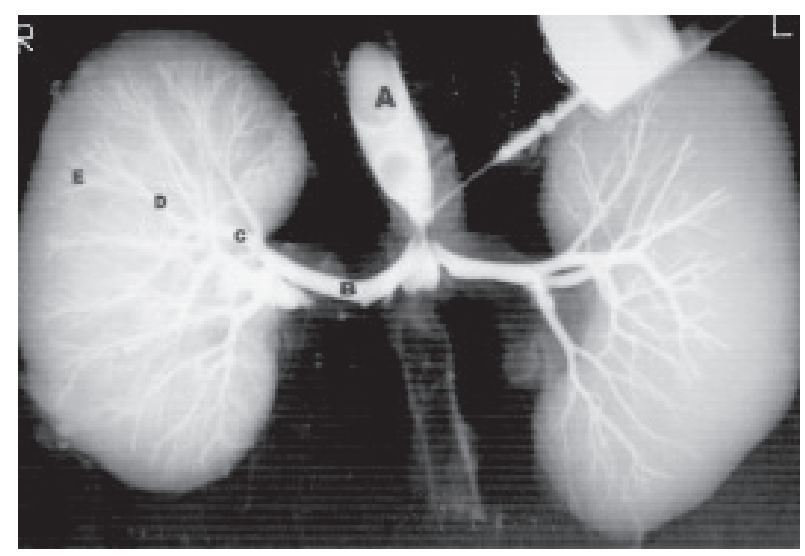

Fig. 2. Renal angiography showing abdominal aorta (A), renal artery (B), segmental artery (C), lobar artery $(D)$ and interlobar artery $(E)$, taken from group $B$ (20-39 years).

\section{Discussion}

Healy ${ }^{4}$ stated that the renal arteries arise as lateral branches of the abdominal aorta; the right one is longer than the left, on account of the position of the aorta. However, the left is at little higher than the right. Dhar \& $\mathrm{Lal}^{11}$ dissected 40 cadaveric specimens and found the mean length of renal artery $31.05 \pm 12 \mathrm{~mm}$ (right) and $25.09 \pm 9.5 \mathrm{~mm}$ (left). Nahar et al. ${ }^{12}$ studied on 60 Bangladeshi cadavers and found the length of the right and left renal arteries $3.30 \pm 0.55 \mathrm{~cm}$ and $2.75 \pm 0.63 \mathrm{~cm}$ in group A (1220 years); $3.86 \pm 0.39 \mathrm{~cm}$ and $3.35 \pm 0.45 \mathrm{~cm}$ in group B (21-40 years); $3.75 \pm 0.45 \mathrm{~cm}$ and $3.23 \pm 0.47 \mathrm{~cm}$ in group C (41-65 years) respectively. Saldarriaga, Pinto $\&$ Ballesteros ${ }^{13}$ studied on a Colombian population and found the average right and left renal artery length $34.6 \mathrm{~mm}$ and $28.6 \mathrm{~mm}$ respectively $(\mathrm{p}<0.001)$. Our results are more or less in agreement with the results previous reports ${ }^{4,11-13}$.

Healy ${ }^{4}$ reported that accessory renal arteries are common (30\% of individuals) and usually arise from the aorta, above or below the main renal artery and follow it to the renal hilum. Rarely, it arises from coeliac trunk, superior mesenteric artery or common iliac arteries. Romanes ${ }^{5}$ stated that accessory renal arteries occur in approximately $25 \%$ of people, while Dhar \& Lal ${ }^{11}$ observed multiple (accessory) renal arteries were observed in $20 \%$ of the specimens with unilateral anomaly $(15 \%)$ being more commonly encountered than bilateral anomaly (5\%). Tarzamni et al. ${ }^{14}$ found an accessory artery in 58 kidneys in a total of 117 patients by using CT angiography and that significantly more often occurred on the right side than on the left side: 38 (32.47\%) right kidneys vs 20 (17.09\%) left kidneys. Our results are more or less similar to the statement of Healy $^{4}$, Romanes ${ }^{5}$ and Tarzamni et al. ${ }^{14}$ (our result is not statistically significant though); however, slightly higher than that of Dhar \& $\mathrm{Lal}^{11}$.

According to the results of the study done by Saldarriaga, Pinto \& Ballesteros ${ }^{13}$, the renal arteries more frequently (85\%) originated from the anterolateral part of the aorta. The right renal artery emerged rostrally in $49.2 \%$, whilst both arteries were located at the same level in $34.4 \%$. The renal poles received a greater contribution from frontal division branches, the upper pole $46.4 \%$ and the lower pole $55.9 \%$. Kosinski \& Oszukowski ${ }^{15}$ showed in a 200 corrosion cast of renal specimens that in 63\% cases, the posterior branch of renal artery ran adjacent to the posterior wall of the renal pelvis, in $18 \%$ it crossed superiorly the wall of superior renal calyx, in $11 \%$ it ran to the posterior labium of renal hilum, in $7 \%$ it was located extra-renal, and $1 \%$ it crossed inferiorly to the wall of superior renal calyx. Those are more or less in agreement with the results of our study. Similar studies were done on the arterial patterns of human stomach ${ }^{29}$ and spleen ${ }^{30}$ 
based on autopsy findings in the same teaching institution \& hospital.

\section{Conclusion}

The results of the present study can be used as a standard reference for the kidneys of Bangladeshi people and to determine the abnormal evidences in forensic and pathologic corpses. However, further studies with larger samples and comparison between sexes are recommended.

\section{Acknowledgement}

We would like to express our gratitude to the authority of Health, Nutrition \& Population Sector Programme (HNPSP) of Directorate General of Health Services (DGHS) of the Government of the People's Republic of Bangladesh, and Dhaka Medical College, Dhaka, for the research grant.

\section{References:}

1. Keele CA, Neil E, Joels N. Samson Wright's applied physiology. $13^{\text {th }}$ ed. New Delhi: Oxford University Press; 2006.

2. Darmady EM, Offer J, Woodhouse MA. The parameters of the ageing kidney. J Pathol 1973; 109(3): 195-207.

3. Sinnatamby CS. Last's anatomy: regional and applied. $12^{\text {th }}$ ed. Edinburgh: Elsevier Churchill Livingstone; 2011.

4. Healy JC. Kidney and ureter. In: Standring S, Borley NR, Collins P, Crossman AR, Gatzoulis MA, Healy JC, et al. eds. Gray's anatomy: the anatomical basis for clinical practice. $40^{\text {th }}$ ed. Edinburgh: Elsevier Churchill Livingstone; 2008.

5. Romanes GJ. Cunningham's manual of practical anatomy. Vol. 3. 15th ed. New Delhi: Thomson Press (India); 2005.

6. Mullick MH. The arterial pattern of human kidney. J Pak Med Assoc 1970; 20: 77-83.
7. Sylve'n M, Boyd M. Renal artery intervention an invasive radiologist's approach. Saudi J Kidney Dis Transpl 2005; 16(2): 181-92.

8. Verma P, Arora AK, Sharma P, Mahajan A. Variations in branching pattern of renal artery and arrangement of hilar structures in the left kidney: clinical correlations, a case report. Ital J Anat Embryol 2012; 117(2): 118-22.

9. Sarfraz R, Tahir M, Sami W. Presegmental arterial pattern of human kidneys in local population. Ann Pak Inst Med Sci 2008; 4(4): 212-5.

10. Boijsen E. Renal angiography: techniques and hazards; anatomic and physiologic considerations. In: Baum S, ed. Abrams' angiography. 4th ed. Philadelphia: Little, Brown \& Co; 1997.

11. Dhar P, Lal K. Main and accessory renal arteries - a morphological study. Ital J Anat Embryol 2005; 110(2): 101-10.

12. Nahar A, Hussain MA, Begum M, Rayhan KA, Faruque ABMO, Ahmed S, et al. Postmortem study of renal artery in Bangladeshi people. Bangladesh J Anat 2008; 6(2): 93-6.

13. Saldarriaga B, Pinto SA, Ballesteros LE. Morphological expression of the renal artery: a direct anatomical study in a Colombian half-caste population. Int J Morphol 2008; 26(1): 31-8.

14. Tarzamni MK, Nezami N, Rashid RJ, Argani H, Hajealioghli P, Ghorashi S. Anatomical differences in the right and left renal arterial patterns. Folia Morphol 2008; 67(2): 104-10.

15. Kosinski H, Oszukowski P. Variations of posterior branch of renal artery course in humans. Med Sci Monit 1997; 3(6): 758-62.

16. Begum GN, Nurunnabi ASM, Shahriah S, Rayhan KA. Cadaver study of the arterial pattern of the stomach in Bangladeshi population. "Health Science” J PMC 2013; 3(1): 3-6.

17. Alim A, Nurunnabi ASM, Mahbub S, Ahmed R, Ara S. Cadaver study on the branching pattern of the splenic artery in a Bangladeshi population. Medicine Today 2014; 26(1): 15-17. 